\title{
Correlation of nasopharyngeal carcinoma with rare earth elements and the Epstein-Barr virus
}

\author{
XIANGMIN ZHANG ${ }^{1 *}$, XIANGFU ZENG ${ }^{2 *}$, LIANBIN LIU $^{3 *}$, XIAOLIN LAN $^{1}$, JING HUANG $^{3}$,

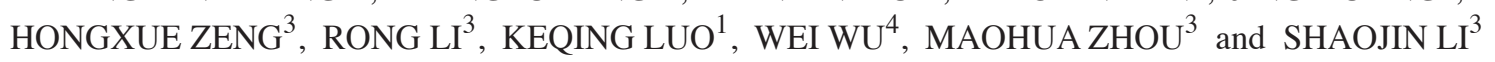 \\ ${ }^{1}$ Department of Head and Neck Surgery, Tumor Hospital of Ganzhou; \\ ${ }^{2}$ Department of General Surgery, The First Affiliated Hospital of Gannan Medical University; ${ }^{3}$ Ganzhou Institute of Cancer \\ Research; ${ }^{4}$ Department of Radiation Oncology, Tumor Hospital of Ganzhou, Ganzhou, Jiangxi 341000, P.R. China
}

Received September 22, 2016; Accepted October 13, 2017

DOI: $10.3892 / 01.2018 .7853$

\begin{abstract}
The concentration and distribution of rare earth elements (REE) in nasopharyngeal carcinoma (NPC) were measured to investigate connections with tumor size, lymph node metastasis, clinical stages, and Epstein-Barr virus (EBV) infection. There were 30 patients with NPC who met the criteria for inclusion in the present study. The EBV copy number, as well as the concentration and distribution of REE, was analyzed. EBV was detected using reverse transcription-polymerase chain reaction, with the concentrations of REE in NPC tissues measured using inductively coupled plasma-tandem mass spectrometry. The mean values were used when comparing concentrations of REE in NPC tissues as the standard deviation of this parameter was the lowest. Light REE had the highest concentrations, followed by medium, and then heavy REE. The concentrations of REE decreased with increasing tumor size and with the presence of lymph node metastasis. The concentrations of REE gradually increased between stage II and IVa, but markedly decreased thereafter. The elements that exhibited the greatest decreases were terbium, holmium and ytterbium. Furthermore, the concentrations of REE in NPC were not associated with $\operatorname{sex}(r=0.301, P=0.106)$ or age $(r=-0.011, P=0.955)$, and were
\end{abstract}

Correspondence to: Professor Shaojin Li, Ganzhou Institute of Cancer Research, Tumor Hospital of Ganzhou, 19 Hua Yuan Qian Road, Ganzhou, Jiangxi 341000, P.R. China

E-mail: 1sj1362@126.com

*Contributed equally

Abbreviations: NPC, nasopharyngeal carcinoma; REE, rare earth elements; EBV, Epstein-Barr virus; ICP-MS/MS, inductively coupled plasma-tandem mass spectrometry; RT-qPCR, reverse transcription-quantitative polymerase chain reaction; $\mathrm{SD}$, standard deviation; T, tumor; N, node; Y, yttrium; La, lanthanum; Lu, lutetium; Yb, ytterbium; Tb, terbium

Key words: nasopharyngeal carcinoma, rare earth element, Epstein-Barr virus, concentration, correlation negatively associated with EBV ( $\mathrm{r}=-0.744, \mathrm{P}<0.001)$. By contrast, the EBV copy number increased alongside advancements in clinical stage. Changes in the concentrations of REE in NPC were more prominent for medium and heavy elements. Additionally, alterations in the concentrations of heavy REE may affect the occurrence and development of NPC.

\section{Introduction}

The Gannan area of China (southern Jiangxi) is praised as the 'rare earth kingdom', processing $>30 \%$ of the country's medium and heavy rare earth reserves and $35 \%$ of the ion-type rare earth reserves; therefore, the region occupies a pivotal position in the global rare earth industry $(1,2)$. However, due to the year-round exploitation of a large amount of rare earth elements (REE), rare earth contamination is a serious concern. REE have special physical and chemical properties, including the ability to enter the human body through the skin, respiratory tract and gastrointestinal tract (3). Following transportation by the blood, REEs may be retained and accumulated in all tissues and organs, leading to an uneven distribution throughout the body $(4,5)$.

The role of REE in the occurrence and development of tumors has received notable attention from the scientific community $(6,7)$; however, studies of their association with nasopharyngeal carcinoma (NPC) remain rare. The present study aimed to investigate the associations of REE and Epstein-Barr virus (EBV) with NPC, to identify their roles in the occurrence and development of NPC. Inductively coupled plasma-tandem mass spectrometry (ICP-MS/MS) was used to measure the concentrations of REE in NPC tissues, and reverse transcription-quantitative polymerase chain reaction (RT-qPCR) was used to detect EBV; subsequently, their correlations with clinical parameters were determined.

\section{Materials and methods}

Ethics statement. The Ethical Committee of the Tumor Hospital of Ganzhou Review Board (Ganzhou, China) approved the study protocol (approval no. 20130102), and the study was conducted in accordance with the principles of the Declaration of Helsinki regarding research involving human subjects. Each 
of the patients provided written informed consent to participate once the nature of the study was explained to them.

Patient inclusion and exclusion criteria. The inclusion criteria were as follows: Nodular or cauliflower-type NPC diagnosed with an electronic nasopharyngoscope; NPC confirmed by pathological examination; patients were undergoing their first treatment; no history of other malignant tumors; a Karnofsky performance score of $\geq 80$ points; an expected survival period of $>6$ months; and patients who volunteered and signed an informed consent form. The exclusion criteria were as follows: Other types of NPC (diagnosed by electronic nasopharyngoscope); recurrent NPC; and the presence of other malignant tumors.

Clinical information. There were 30 patients with NC who met the inclusion criteria and were enrolled in the study between January 2013 and June 2014. The cohort included 17 males and 13 females, 24-78 years of age (mean, 47 years). The pathological findings from the biopsy analyses revealed 1 case of keratinizing squamous cell carcinoma, 28 cases of non-keratinizing squamous cell carcinoma and 1 case of undifferentiated carcinoma combined with neuroendocrine differentiation (Table I).

Pre-treatment of tissue specimens. In total, NPC tissue specimens were obtained from 30 patients who had originated from the rare earth-rich region of Gannan. It was particularly important that patients originated from this region as this population exhibits an increased incidence of NPC. Endoscopy-guided biopsy was completed in the Department of Endoscopy between January 2013 and June 2014, Ganzhou Tumor Hospital (Jiangxi, China) to remove NPC samples. NPC tissues were collected and stored in a $-80^{\circ} \mathrm{C}$ refrigerator. For detection assays, the samples were lyophilized at $35^{\circ} \mathrm{C}$ for $1 \mathrm{~h}$, and then ground using an agate mortar to form a powder. Samples were then placed in a polyethylene bottle and stored in a vacuum freeze drying machine (cat. no. FD-1A-50, Shanghai Bilon Instrument Co., Ltd, Shanghai, China) at $-35^{\circ} \mathrm{C}$ and were vacuumed at 15 pa for $1 \mathrm{~h}$, or until dry. Ultrapure nitric acid (cat. no. 140730-1, China Xilong Chemical Co., Ltd., Guangdong, China) and perchloric acid (cat. no. 20140412; Tianjin Kemiou Chemical Reagent Co., Ltd., Tianjin, China) reagents were used. For water, $18 \mathrm{M} \Omega$ ultrapure water was prepared using a Water Purification System (Milli-Q ${ }^{\circledR}$ Advantage A10; Merck KGaA, Darmstadt, Germany). For each powdered sample, $10 \mathrm{mg}$ was precisely weighed and dissolved in $1 \mathrm{ml}$ of mixed acid $\left(68 \% \mathrm{HNO}_{3} ; 70 \% \mathrm{HClO}_{4} ; 10: 1\right)$. The prepared mixed acid was slowly heated in a water-bath $\left(65^{\circ} \mathrm{C}\right)$ for digestion until the solution became a light yellow transparent liquid, indicating that the powder was fully dissolved. The volume was then increased to $2 \mathrm{ml}$ with distilled water, and this solution was used for measuring the REE concentrations. A blank control was prepared using the aforementioned solution and processed under the same conditions. The mass ratio was calculated according to the measured blank and sample concentrations, and the dry weight of the samples.

Sample measurement. Measurement of the concentrations of 15 REE, including yttrium (Y), lanthanum (La) and lutetium
(Lu), was performed by the National Tungsten \& Rare-Earth Product Quality Supervision Testing Center, using an Agilent 8000 ICP-MS/MS (Agilent Technologies Inc., Santa Clara, CA, USA). The detection limit was $0.002-0.025 \mathrm{ng} / \mathrm{ml}$. Indium and caesium were used as internal standard elements for compensation to inhibit the sensitivity drift caused by the matrix and interface effects. The instrument automatically calibrated interference caused by oxides. The standard recovery rates of the 15 REE were between 93.8-108.8\%.

EBV measurement. RT-qPCR was performed in an ABI 7500 machine (Thermo Fisher Scientific, Inc., Waltham, MA, USA) with a nucleic acid amplification (PCR) fluorescent quantitative detection kit for EB virus (Da An Gene Co, Guangdong, China). DNA extraction was performed using DNAzol ${ }^{\mathrm{TM}}$ reagent (cat. no. 10503027; Thermo Fisher Scientific Inc.) according to the manufacturer's instructions. The amplified target was from the Epstein-Barr virus nuclear antigen (EBNA-1) fragment of EBV. The upstream primer, downstream primer and probes were included in the Da An Gene Co., Ltd., reagent kit. The 5'-end of the probe was labeled with the fluorophore carboxyfluorescein (FAM), while the 3'-end of the probe was labeled with the fluorescence-quenching molecule carboxytetramethylrhodamine. The samples were divided into 4 groups according to the concentration of EBV: Negative, $\leq 500 \mathrm{IU} / \mathrm{ml}$; weakly positive, 501-20,000 IU/ml; positive, 20,001-1,000,000 IU/ml; and strongly positive, $\geq 1,000,001 \mathrm{IU} / \mathrm{ml}(8,9)$.

Statistical methods. SPSS version 22.0 (IBM Corp., Armonk, NY, USA) statistical software package was used for data processing. Standard deviations (SD) of the mean values, geometric mean values and median values of the representative NPC tissue samples were calculated. The parameter with the lowest SD was selected as the representative indicator for the present study. The mean values and overall deviations for all REE concentrations in NPC tissues were calculated and analyzed using the compare means function in the SPSS software package. The normality test was performed using the Kolmogorov-Smirnov test and the Shapiro-Wilk test. When $\mathrm{P} \sim 1$, it was considered to indicate an improved fit for normal distribution. The Kruskal-Wallis method was performed to examine whether the concentrations of REE in NPC tissues were significantly different at distinct clinical stages. Correlations were analyzed using the Spearman's rank correlation analysis, with $\mathrm{P}=0.05$ considered to indicate a statistically significant difference.

The distributions of light, medium and heavy, and/or light vs. heavy, REE and the ratios between the light and heavy element concentrations were calculated. In the calculation of light, medium and heavy REE concentrations, the light $\mathrm{REE}$ concentration referred to the total concentration of all elements from La to neodymium; the medium REE concentration referred to the total concentration of all elements from samarium to holmium; and the heavy REE concentration referred to the total concentration from erbium to $\mathrm{Lu}$. For the calculation of light vs. heavy REE concentrations, the light REE concentration referred to the total concentration of elements from La to europium; and the heavy REE concentration referred to the total concentration from gadolinium to $\mathrm{Lu}$. The concentration of $\mathrm{Y}$ was not included in the present 
Table I. General clinical information of the patients enrolled in the present study.

\begin{tabular}{lc}
\hline Categories & Study subjects $(\mathrm{n}=30)$ \\
\hline Age range (years) & $24-78$ \\
Median age & 47.0 \\
Sex & \\
Male & 17 \\
Female & 13 \\
Male:female ratio & $1.31: 1$ \\
Stage & \\
0 & 0 \\
I & 0 \\
II & 5 \\
III & 14 \\
IVa & 10 \\
IVb & 1 \\
IVc & 0 \\
\hline
\end{tabular}

study as a REE. After the REE were normalized using the recommended mean values for chondrite, their distributions in cancer tissues were compared.

\section{Results}

Concentrations of REE in NPC tissues. The mean, geometric mean and median concentrations of REE in NPC tissues were calculated, along with the corresponding SD, which revealed that the SD was lowest for the mean (Table II).

Trends in REE concentrations at the tumor (T) stage of NPC. The mean concentrations of REE at the T stage of NPC are demonstrated in Table III, grouped according to light, medium and heavy elements. Light and medium REE each exhibited a decreasing trend, while heavy elements demonstrated a periodically changing trend (Fig. 1). When divided into only light and heavy REE, both groups showed gradually decreasing trends (Fig. 2).

Trends in REE concentrations at the node $(N)$ stage of NPC. The mean concentrations of REE at the N stage of NPC are listed in Table IV. When grouped as light, medium, and heavy elements, no groups exhibited significant trends (Fig. 3). However, when grouped according to light and heavy elements, each group exhibited a decreasing trend from stage N0 to N1, remained steady from stage N1 to N2, and increased from stage N2 to N3 (Fig. 4).

Trends in REE concentrations at each clinical stage of NPC. The mean concentrations of REE at each clinical stage of NPC are presented in Table V. When REE were classified as light, medium and heavy, the concentrations of light and medium REE gradually increased from stage II to IVa, and then started to decrease. Decreasing trends in $\mathrm{Y}$ and heavy REE began earlier; from stage IVa to IVb, the absolute value of the concentration of $\mathrm{Y}$ was decreased by $13.30 \%$, and the concentrations of light, medium and heavy REEs was decreased by 27.78 , 42.62 and $41.32 \%$, respectively. The change in the concentrations of light REE was the largest, while the decrease in medium REE concentrations was the greatest, followed by that of heavy REE; the change in Y was the smallest. Overall, light, middle and heavy REE changed by 27.78, 42.62 and $59.25 \%$, respectively, between their peaks and lowest points at stage IVb. The changes in the concentrations of light REE and $\mathrm{Y}$ were relatively minor compared with the greater shifts in heavy REE, which were observed with disease progression. Medium REE also indicated prominent changes, but not until the late stages of NPC, while the changes in heavy REE were already notable at moderate disease stages (Fig. 5).

When grouped as light vs. heavy REE, the concentrations of light REE in the tissues of the patients with NPC were largely consistent across different stages, with a slight increase from stage II to III, no major change from stage III to IVa and a strong decrease from stage IVa to IVb (26.81\%). Heavy REE exhibited an even higher decrease of $48.52 \%$ from stage IVa to IVb (Fig. 6). The variation in the absolute values of light REE was the highest, though substantial variation was also observed for medium and heavy REE. The elements with the greatest change were terbium (Tb), Ho and ytterbium ( $\mathrm{Yb}$ ) (Fig. 7).

Correlations of REE with sex, age and EBV in NPC. Non-parametric tests demonstrated that the concentrations of REE in patients with NPC were not associated with sex $(\mathrm{r}=0.301, \mathrm{P}=0.106)$ or age $(\mathrm{r}=-0.011, \mathrm{P}=0.955)$. However, there was a strong negative correlation between the concentrations of REE and the EBV copy number ( $\mathrm{r}=-0.744, \mathrm{P}<0.001$; Table VI). With increasing levels of EBV, the total concentration of REE demonstrated a decreasing trend, and the majority of individual REE gradually decreased in concentration. Judging by the percentage of variation, medium and heavy elements indicated the greatest changes. Thus, the association of EBV with REE changes in patients with NPC was more apparent for the medium and heavy elements (Figs. 8 and 9).

\section{Discussion}

The potentially toxic effects of REE on human health are a focus of numerous recent studies $(10,11)$. REE have various biological activities, affecting cell proliferation and growth through changes in ATPase activity on the cell surface, intracellular and extracellular ion exchange, cell division and DNA synthesis (12-15). Their functions in tumors are particularly prominent.

REE are closely associated with the occurrence and development of tumors. In 1971, Schroeder and Mitchener (2) confirmed that $\mathrm{Y}\left(\mathrm{NO}_{3}\right)_{3}$ water containing heavy REE had carcinogenic effects in rats. REE can cause lipid peroxidation injury, which can induce DNA base damage and strand breakage as well as the production of numerous types of fluorescent substances $(16,17)$. The end product, malondialdehyde, can form DNA adducts, which further causes mutations and tumorigenesis $(10,18)$. In addition, the process of lipid peroxidation produces a variety of active free radicals, which have mutagenic effects (19). However, some studies have also revealed that REE can have antitumor effects. Giri et al (20) 
Table II. Comparison of mean values, geometric mean values, median values, and SD of REE in NPC (ng/g).

\begin{tabular}{|c|c|c|c|c|c|c|c|}
\hline \multirow{3}{*}{$\begin{array}{l}\text { Elements in } \\
\text { NPC tissues }\end{array}$} & \multirow[b]{3}{*}{ Mass } & \multirow{2}{*}{\multicolumn{2}{|c|}{ Mean }} & \multicolumn{2}{|c|}{ Geometric mean } & \multicolumn{2}{|r|}{ Median } \\
\hline & & & & \multirow{2}{*}{$\begin{array}{c}\text { Geometric } \\
\text { mean }\end{array}$} & \multirow{2}{*}{$\begin{array}{c}\text { Variance calculated } \\
\text { using geometric mean }\end{array}$} & \multirow[b]{2}{*}{ Median } & \multirow{2}{*}{$\begin{array}{l}\text { Variance calculated } \\
\text { using median }\end{array}$} \\
\hline & & Mean & SD & & & & \\
\hline Yttrium & 89 & 22.3880 & 7.8422 & 21.2478 & 7.9275 & 18.6600 & 8.7108 \\
\hline Lanthanum & 139 & 32.4425 & 9.9812 & 31.1723 & 10.0644 & 29.5700 & 10.3997 \\
\hline Cerium & 140 & 56.0563 & 18.8704 & 53.5996 & 19.0353 & 51.4100 & 19.4535 \\
\hline Praseodymium & 141 & 19.5743 & 12.6486 & 17.8561 & 12.7687 & 15.2100 & 13.4048 \\
\hline Neodymium & 146 & 72.2203 & 44.5399 & 65.8566 & 45.0076 & 56.8100 & 47.2171 \\
\hline Samarium & 147 & 5.5647 & 3.8381 & 4.9980 & 3.8812 & 4.3500 & 4.0320 \\
\hline Europium & 151 & 5.6570 & 2.1905 & 5.2273 & 2.2334 & 5.7700 & 2.1936 \\
\hline Gadolinium & 157 & 96.1065 & 288.2334 & 23.6737 & 297.4995 & 14.6452 & 299.9054 \\
\hline Terbium & 159 & 5.0213 & 5.0379 & $<0.0001$ & 7.1734 & 4.0850 & 5.1270 \\
\hline Dysprosium & 162 & 13.2283 & 6.5979 & 12.3694 & 6.6555 & 11.5600 & 6.8126 \\
\hline Holmium & 165 & 3.0120 & 2.4210 & 2.4631 & 2.4846 & 1.9750 & 2.6408 \\
\hline Erbium & 166 & 2.4853 & 0.9046 & 2.3437 & 0.9160 & 2.1650 & 0.9616 \\
\hline Thulium & 169 & 0.2047 & 0.1323 & $<0.0001$ & 0.2473 & 0.1900 & 0.1333 \\
\hline Ytterbium & 172 & 4.6663 & 5.9985 & 3.2258 & 6.1749 & 2.4900 & 6.3940 \\
\hline Lutetium & 175 & 0.8323 & 0.3629 & 0.7681 & 0.3688 & 0.7150 & 0.3822 \\
\hline
\end{tabular}

REE, rare earth elements; NPC, nasopharyngeal carcinoma; SD, standard deviation.

Table III. Mean concentrations of light, medium and heavy REE, or light vs. heavy REE at the T stage of NPC (ng/g).

\begin{tabular}{lccccc}
\hline & \multicolumn{3}{c}{ Method 1 } & & \multicolumn{2}{c}{ Method 2 } \\
\cline { 2 - 4 } T stage & Light REE & Medium REE & Heavy REE & & Light REE \\
\hline T1 & 64.72 & 15.46 & 2.36 & 45.48 & 11.03 \\
T2 & 47.27 & 8.74 & 1.49 & 33.29 & 3.97 \\
T3 & 42.87 & 7.75 & 2.57 & 30.55 & 5.59 \\
T4 & 39.79 & 8.52 & 1.93 & 28.24 & 6.02 \\
\hline
\end{tabular}

REE, rare earth elements; T, tumor; NPC, nasopharyngeal carcinoma.

demonstrated that the intraperitoneal injection of $0.1 \mathrm{mg} / \mathrm{kg}$ cerium oxide nanoparticles into mice implanted with A2780 ovarian cancer cells significantly inhibited the growth of the implanted tumor. Su et al (21) indicated that treatment with lanthanum citrate for $48 \mathrm{~h}$ induced anoikis of HeLa cells, thus inhibiting tumor growth. The present study determined that the concentrations of certain REE, including $\mathrm{Gd}$, Tb and $\mathrm{Yb}$, changed notably with the progression of NPC, while others, including Y, La and cerium, exhibited only small changes. The concentrations of REE increased from stage II to IVa and then greatly decreased from IVa to IVb. Notably, the concentrations of medium and heavy REE decreased with disease progression.

EBV is closely associated with the occurrence and development of NPC $(22,23)$. The initial report by Mutirangura et al (24) in 1998 revealed that EBV DNA copy number was significantly higher in the peripheral blood of patients with NPC than in individuals without the disease; since then, a large amount of evidence has demonstrated that higher plasma levels of EBV DNA are associated with more advanced clinical stages and more extensive lymph node metastases (25-27). Therefore, plasma EBV DNA not only serves as a useful marker for the screening and early diagnosis of NPC but also has significance in clinical staging, prognosis determination, and the monitoring of recurrence and distant metastasis in patients with NPC (28-30). This present study supports prior studies that indicated that EBV copy number increased with advancements in clinical stage. In addition to this increase in the EBV copy number, the concentrations of all REE demonstrated a decreasing trend with progression of the disease. The majority of individual REE also gradually decreased, and their concentrations indicated a strong negative correlation with EBV levels. The greatest proportional changes were observed with the medium and heavy REE. The 
Table IV. Mean concentrations of light, medium, and heavy or light vs. heavy REE at the N stage of NPC (ng/g).

\begin{tabular}{lcccccc}
\hline & \multicolumn{3}{c}{ Method 1 } & & \multicolumn{2}{c}{ Method 2 } \\
\cline { 2 - 3 } N stage & Light REE & Medium REE & Heavy REE & & Light REE & Heavy REE \\
\hline N0 & 62.18 & 11.76 & 1.91 & & 44.18 & 7.73 \\
N1 & 42.86 & 9.12 & 1.94 & & 30.65 & 6.23 \\
N2 & 42.40 & 7.48 & 2.42 & & 29.89 & 5.58 \\
N3 & 60.22 & 10.82 & 1.27 & & 41.60 & 7.66 \\
\hline
\end{tabular}

REE, rare earth elements; N, node; NPC, nasopharyngeal carcinoma.

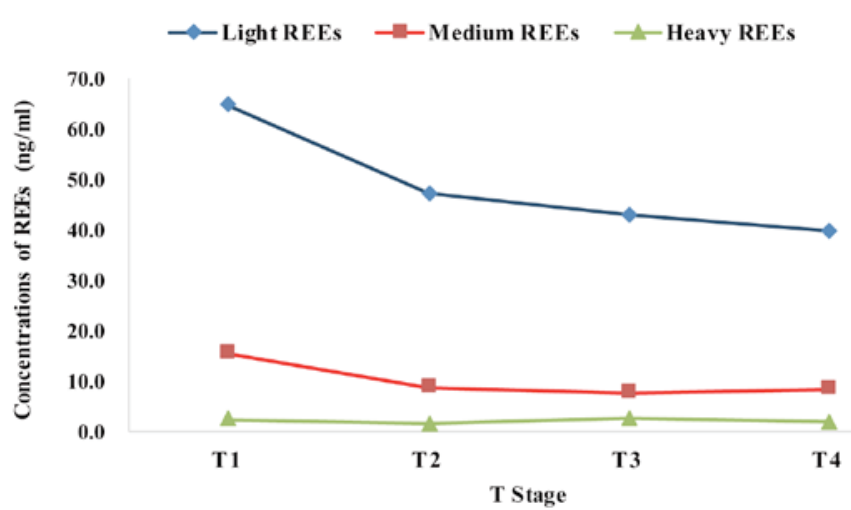

Figure 1. Trends in the concentrations of light, medium, and heavy REEs at the tumor stage of nasopharyngeal carcinoma. REE, rare earth element; $\mathrm{T}$, tumor.

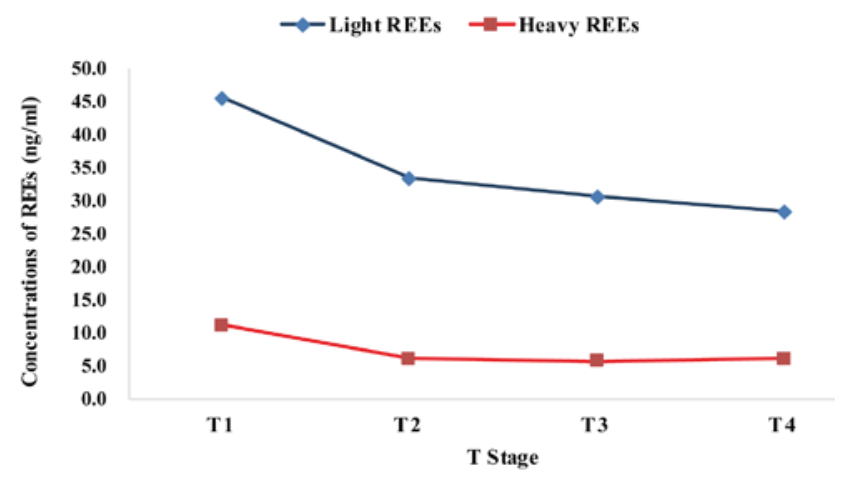

Figure 2. Trends in the concentrations of light and heavy REEs at the tumor stage of nasopharyngeal carcinoma. REE, rare earth element; $\mathrm{T}$, tumor.

association of EBV with the changes in REE in patients with NPC was clearest between the medium and heavy elements. Therefore, it is speculated that changes in the concentrations of medium and heavy REE may affect the occurrence and development of NPC.

Chemical carcinogens can enhance EBV activation, change gene expression in NPC patients and induce tumors (31). EBV infection, chemical carcinogens and the interaction between these factors could all serve important roles in the development of NPC $(32,33)$. A previous study (34) proposed that REE have dual, dose-dependent effects on cellular physiology, with high doses exerting inhibitory effects on cell growth and low

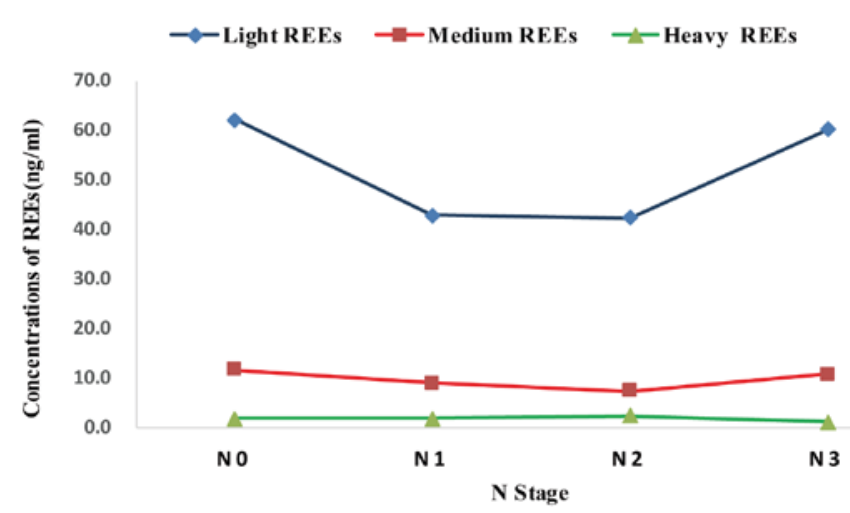

Figure 3. Trends in the concentrations of light, medium, and heavy REEs at the node stage of nasopharyngeal carcinoma. REE, rare earth element; $\mathrm{N}$, node.

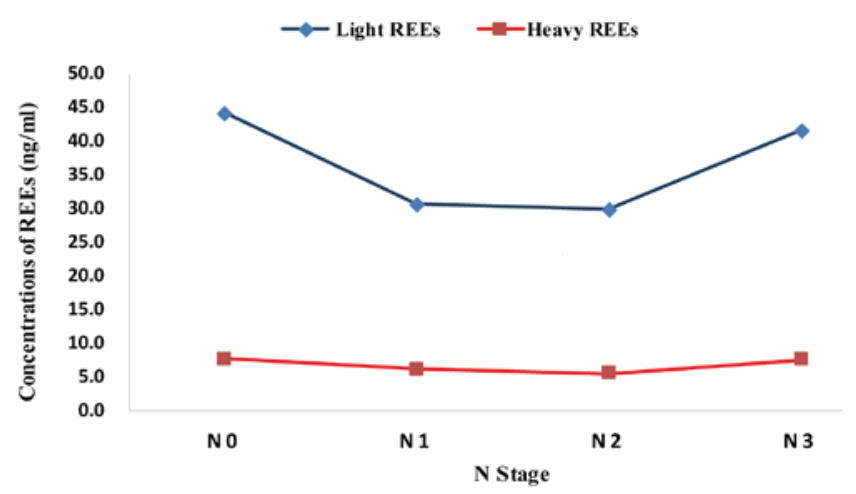

Figure 4. Trends in the concentrations of light and heavy REEs at the node stage of nasopharyngeal carcinoma. REE, rare earth element; N, node.

doses promoting growth. However, this pattern varies across the different types of REE, inverting completely in certain cases, having more prominent effects in tumors. The present study found that compared with the mean concentration and distribution values of REE in the chondrite; NPC tissues demonstrated a relative loss of heavy REE and an enrichment of light REE. Throughout the development and progression of NPC, heavy REE varied the most, with reductions in concentration $\leq 41.32-48.52 \%$. Elucidation of the mechanism underlying this loss of heavy REE and the enrichment of light REEs in NPC will require further animal experiments and clinical studies. 
Table V. Mean concentrations of light, medium and heavy REE, or light vs. heavy REE at each clinical stage of NPC (ng/g).

\begin{tabular}{lccccccc}
\hline & & \multicolumn{3}{c}{ Method 1 } & & \multicolumn{2}{c}{ Method 2 } \\
\cline { 3 - 5 } \cline { 7 - 8 } TNM stage & $\mathrm{Y}$ & Light REE & Medium REE & Heavy REE & & Light REE & Heavy REE \\
\hline II & 22.1400 & 44.5306 & 8.1771 & 1.6255 & & 31.7084 & 5.4296 \\
III & 23.8560 & 45.5145 & 8.9385 & 2.4962 & & 32.3540 & 6.4212 \\
IVa & 20.8853 & 45.9175 & 9.2184 & 1.7335 & & 32.2465 & 6.5207 \\
IVb & 18.1078 & 33.1638 & 5.2899 & 1.0173 & & 23.6012 & 3.3571 \\
\hline
\end{tabular}

REE, rare earth elements; TNM, tumor node metastasis; NPC, nasopharyngeal carcinoma.

Table VI. Associations between REE, sex, age and EBV in NPC.

\begin{tabular}{lrcr}
\hline Type & $\mathrm{n}$ & $\mathrm{r}$ & P-value \\
\hline Sex & & & \\
$\quad$ Male & 17 & & \\
Female & 13 & 0.301 & 0.106 \\
Age (years) & & & \\
$23-37$ & 2 & & \\
$37-51$ & 16 & & \\
$51-65$ & 7 & & \\
$65-79$ & 5 & -0.011 & \\
EBV $(\mathrm{IU} / \mathrm{ml})$ & & & \\
$\leq 500$ & 7 & & \\
$501-20,000$ & 8 & & \\
$20,001-1,000,000$ & 6 & & \\
$\geq 1,000,000$ & 9 & -0.744 & \\
\hline
\end{tabular}

EBV, Epstein-Barr virus; NPC, nasopharyngeal carcinoma; REE, rare earth elements.

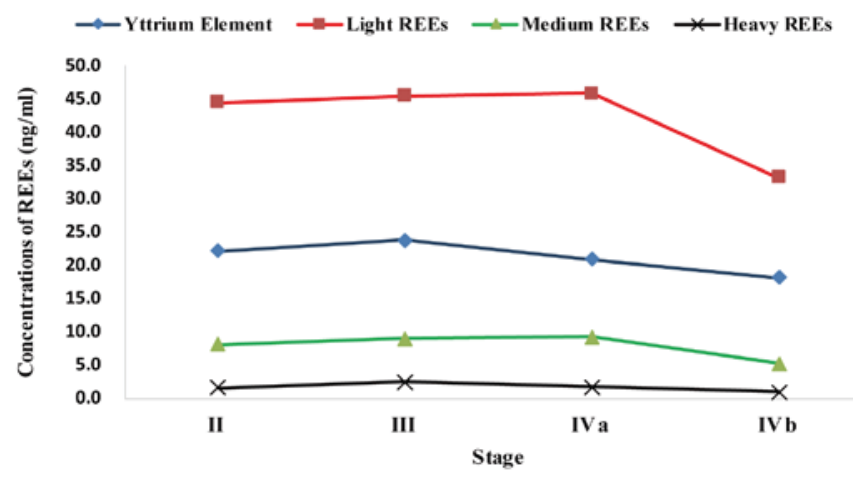

Figure 5. Trends in the concentrations of light, medium, and heavy REEs at clinical stages of nasopharyngeal carcinoma. REE, rare earth element.

The present study did not include a non-NPC control group. A survey was performed on the family members of patients with NPC and also members of the public prior to performing the study and determined that healthy family members and the public would not agree to have their nasopharyngeal

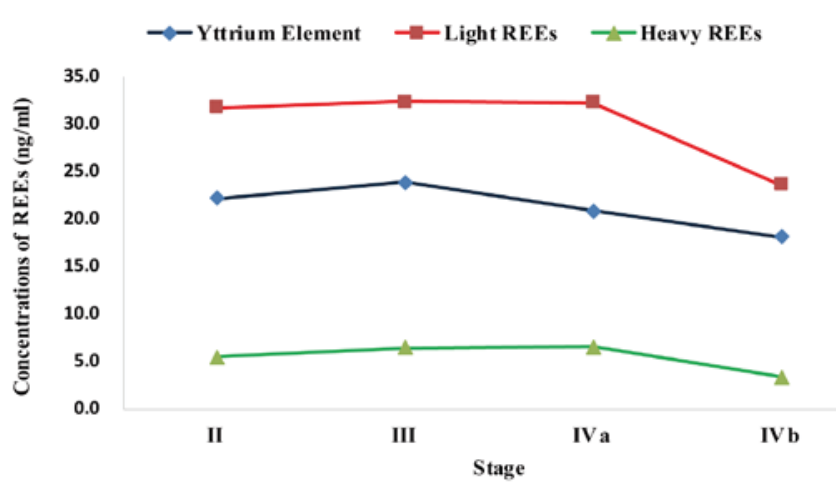

Figure 6. Trends in the concentrations of light and heavy REEs at clinical stages of nasopharyngeal carcinoma. REE, rare earth element.

tissues collected. Collection of normal nasopharyngeal tissue samples involves significant trauma and pain and carries a risk of massive bleeding. The Ethics Committee also rejected the proposal for setting up a control group following careful consideration. The results in the current study may also have certain biases. First, the overall sample size was small. During the calculation of the mean concentrations of all REE in NPC tissues and the overall deviations, samples were repeatedly used, and the $95 \%$ confidence interval method was used to expand the number of samples for prediction of the overall mean value. Second, non-tumor tissues may have inadvertently been included when the diagnosed nodular or cauliflower-type NPC tissues were collected using an electronic nasopharyngoscope for REE detection. Third, to reduce bleeding, non-tumor tissues and deep-layer tissues were not collected. As a result, the collected tissues were small, and specimen processing may have introduced errors. In addition, despite being able to determine EBV levels in serum, due to the limitation of the NPC tissue specimens, EBV levels could not be determined in tumor tissues. We did not determine EBV levels in the tumor tissues.

Although the present study did not completely elucidate the associations between the occurrence and development of NPC, and changes in the distribution and concentration of REE in NPC tissues, the results provide insight for further studies on this topic, including studies on the correlation of NPC with REE and EBV.

In conclusion, the concentrations of REE in NPC tissues were not associated with sex or age, but gradually increased 


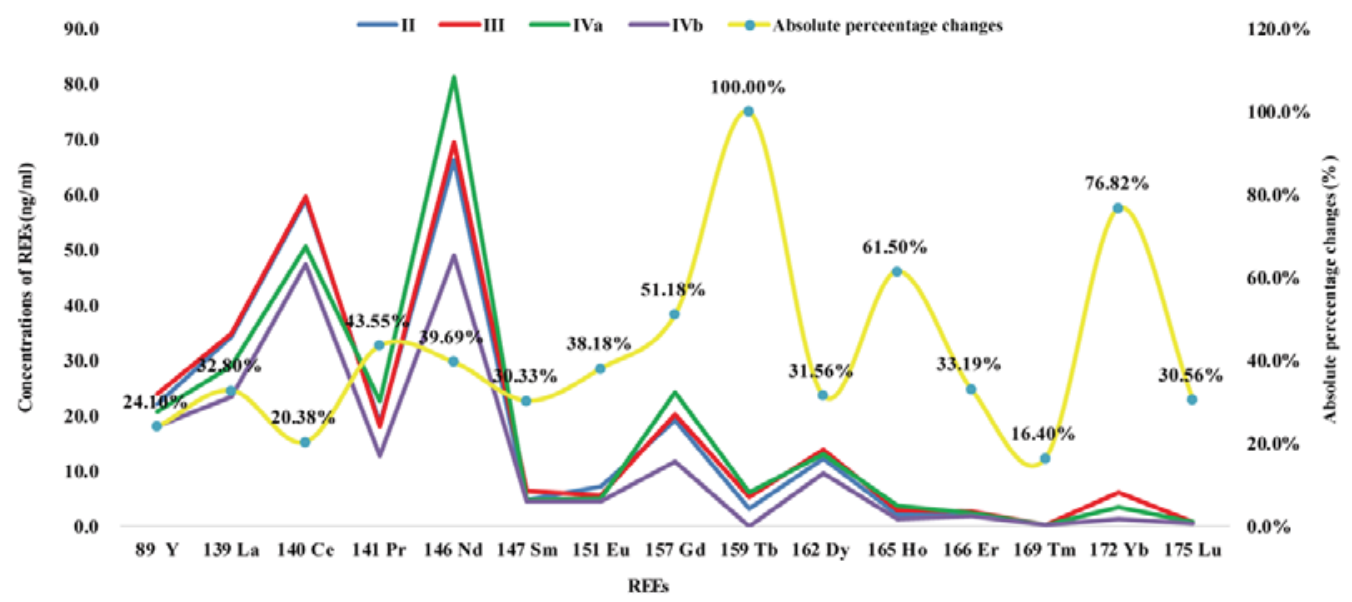

Figure 7. Association of REEs with clinical stages of nasopharyngeal carcinoma. REE, rare earth element.
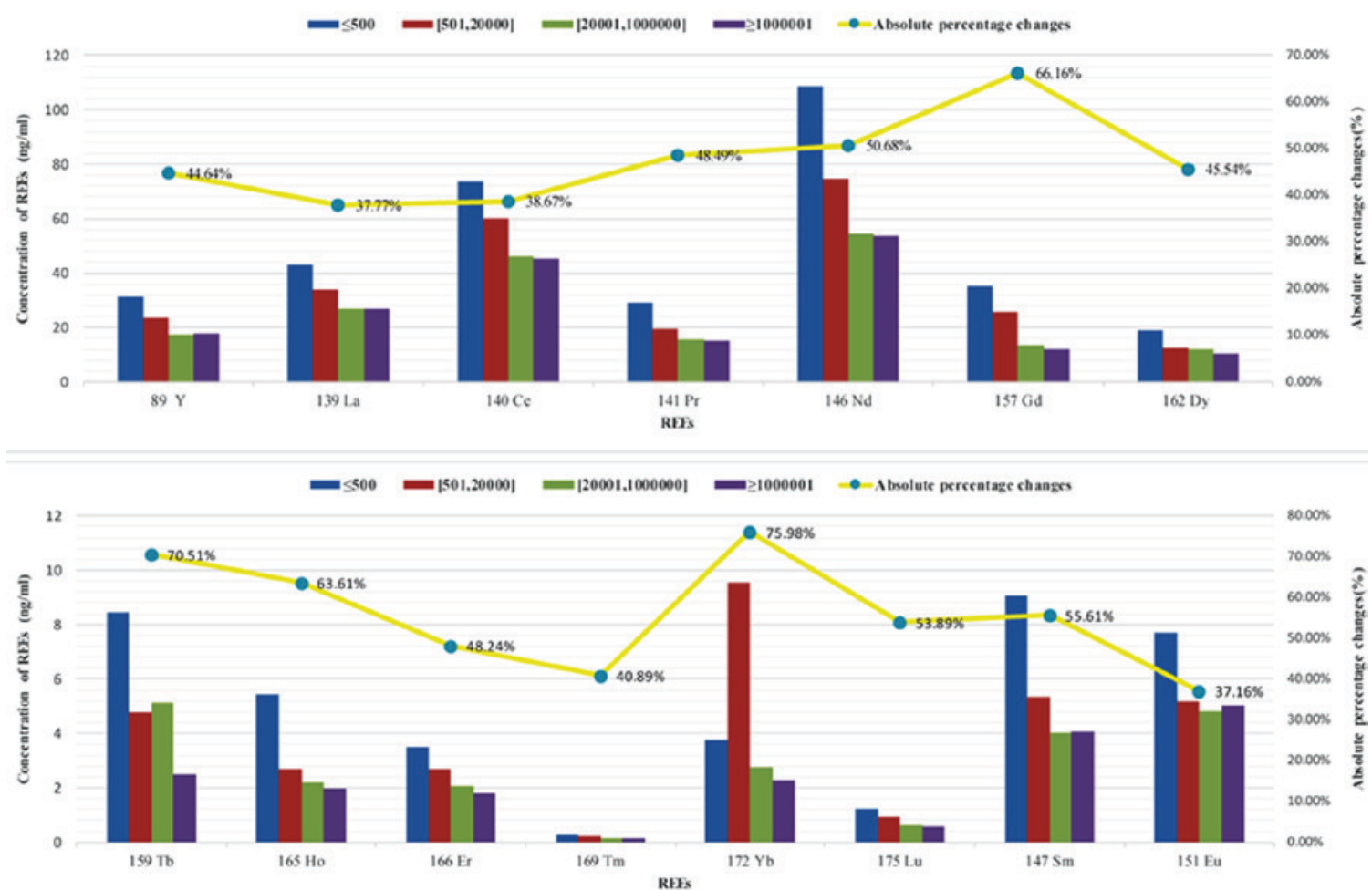

Figure 8. The effect of Epstein-Barr virus levels on changes in the concentrations of REEs in nasopharyngeal carcinoma. REE, rare earth element; EBV, Epstein-Barr virus.

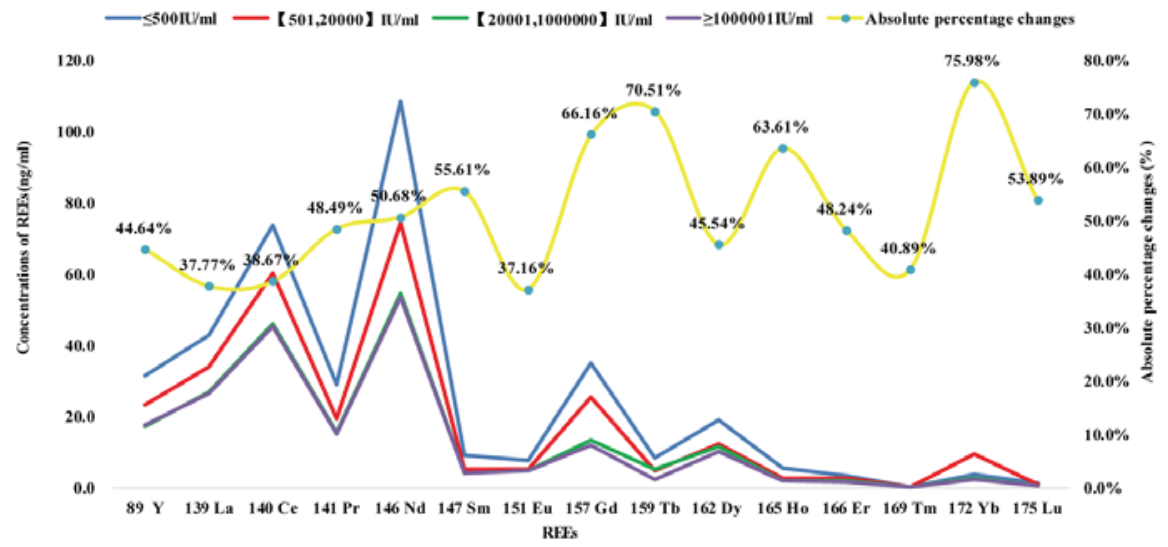

Figure 9. The effect of REEs concentrations on changes in Epstein-Barr virus levels. REE, rare earth element. 
between stages II and IVa prior to significantly decreasing following stage IVa. By contrast, the EBV copy number increased with advanced clinical stages. Changes in the concentrations of REE in NPC were more prominent for medium and heavy elements. Shifts in the concentrations of heavy REE may affect the occurrence and development of NPC.

\section{Acknowledgements}

The present study was supported by the Natural Science Foundation of Jiangxi Province (grant no. 20122BAB205048).

\section{References}

1. Liu HP: A discussion of the development of rare earth industry of Ganzhou. Nonferrous Metals Science and Engineering: 101-104, 2012 (In Chinese).

2. Xu ST: Study on the problems and countermeasures of Ganzhou sustainable development of rare earth industry. J Jiangxi Univ Sci Technol: 47-51, 2014 (In Chinese)

3. Chen Z, Liu Y, Cheng W, Zhang L, Li H and Wang Y: The environmental toxicology of rare earth elements $\left({ }^{147} \mathrm{Pm},{ }^{141} \mathrm{Ce},{ }^{147} \mathrm{Nd}\right)$ and their safety elvaluation in environment. China Nuclear Sci Technol Rep: 33, 2001 (In Chinese).

4. Ohnishi K, Usuda K, Nakayama S, Sugiura Y, Kitamura Y, Kurita A, Tsuda Y, Kimura M and Kono K: Distribution, elimination, and renal effects of single oral doses of europium in rats. Biol Trace Elem Res 143: 1054-1063, 2011.

5. Guo ZY, Zhang YS and Zhang HJ: Pathway, distribution, metabolism and toxicity of exogenous rare earth in animals. Chin Rare Earths: 61-64, 1997 (In Chinese).

6. Schroeder HA and Mitchener M: Scandium, chromium(VI), gallium, yttrium, rhodium, palladium, indium in mice: Effects on growth and life span. J Nutr 101: 1431-1437, 1971.

7. Smith JB and Smith L: Initiation of DNA synthesis in quiescent Swiss 3T3 and 3T6 cells by lanthanum. Biosci Rep 4: 777-782, 1984

8. Lo YM, Chan LY, Lo KW, Leung SF, Zhang J, Chan AT, Lee JC, Hjelm NM, Johnson PJ and Huang DP: Quantitative analysis of cell-free Epstein-Barr virus DNA in plasma of patients with nasopharyngeal carcinoma. Cancer Res 59: 1188-1191, 1999.

9. Shotelersuk K, Khorprasert C, Sakdikul S, Pornthanakasem W, Voravud $\mathrm{N}$ and Mutirangura A: Epstein-Barr virus DNA in serum/plasma as a tumor marker for nasopharyngeal cancer. Clin Cancer Res 6: 1046-1051, 2000.

10. Sojka B, Kuricova M, Liskova A, Bartusova M, Banski M, Misiewicz J, Dusinska M, Horvathova M, Jahnova E, Ilavska S, et al: Hydrophobic sodium fluoride-based nanocrystals doped with lanthanide ions: Assessment of in vitro toxicity to human blood lymphocytes and phagocytes. J Appl Toxicol 34: 1220-1225, 2014.

11. Pagano G, Guida M, Tommasi F and Oral R: Health effects and toxicity mechanisms of rare earth elements-Knowledge gaps and research prospects. Ecotoxicol Environ Saf 115: 40-48, 2015.

12. Cao R, Huang XH and Zhou Q: Research on Molecular Biomarker of Rare Earths Ions Ecotoxicity. System Sci Comprehensive Studies Agriculture, 2007.

13. Fernando KC and Barritt GJ: Characterisation of the divalent cation channels of the hepatocyte plasma membrane receptor-activated $\mathrm{Ca} 2+$ inflow system using lanthanide ions. Biochim Biophys Acta 1268: 97-106, 1995.

14. Matsumoto Y and Komiyama M: DNA hydrolysis by rare-earth metal ions. Nucleic Acids Symp Ser: 33-34, 1992.

15. Leuratti C, Singh R, Lagneau C, Farmer PB, Plastaras JP, Marnett LJ and Shuker DE: Determination of malondialdehyde-induced DNA damage in human tissues using an immunoslot blot assay. Carcinogenesis 19: 1919-1924, 1998.

16. Leuratti C, Singh R, Lagneau C, Farmer PB, Plastaras JP, Marnett LJ and Shuker DE: Determination of malondialdehyde-induced DNA damage in human tissues using an immunoslot blot assay. Carcinogenesis 19: 1919-1924, 1998.

17. Mittal S and Pandey AK: Cerium oxide nanoparticles induced toxicity in human lung cells: Role of ROS mediated DNA damage and apoptosis. Biomed Res Int 2014: 891934, 2014.
18. Huang PJ, Vazin M, Matuszek $\dot{Z}$ and Liu J: A new heavy lanthanide-dependent DNAzyme displaying strong metal cooperativity and unrescuable phosphorothioate effect. Nucleic Acids Res 43: 461-469, 2015.

19. Lin WT, Huang PJ, Pautler R and Liu J: The group trend of lanthanides binding to DNA and DNAzymes with a complex but symmetric pattern. Chem Commun (Camb) 50: 11859-11862, 2014.

20. Giri S, Karakoti A, Graham RP, Maguire JL, Reilly CM, Seal S, Rattan R and Shridhar V: Nanoceria: A Rare-earth nanoparticle as a novel Anti-angiogenic therapeutic agent in ovarian cancer. PLoS One 8: e54578, 2013.

21. Su X, Zheng X and Ni J: Lanthanum citrate induces anoikis of Hela cells. Cancer Lett 285: 200-209, 2009.

22. Perri F, Della Vittoria Scarpati G, Giuliano M, D'Aniello C, Gnoni A, Cavaliere C, Licchetta A and Pisconti S: Epstein-Barr virus infection and nasopharyngeal carcinoma: The other side of the coin. Anticancer Drugs 26: 1017-1025, 2015.

23. Lim CS, Goh SL, Kariapper L, Krishnan G, Lim YY and Ng CC: Inclusion bodies of recombinant Epstein-Barr virus capsid antigen p18 as potential immobilized antigens in enzyme immunoassays for detection of nasopharyngeal carcinoma. Clin Chim Acta 448: 206-210, 2015.

24. Mutirangura A,Pornthanakasem W, Theamboonlers A, Sriuranpong V, Lertsanguansinchi P, Yenrudi S, Voravud N, Supiyaphun P and Poovorawan Y: Epstein-Barr viral DNA in serum of patients with nasopharyngeal carcinoma. Clin Cancer Res 4: 665-669, 1998.

25. Xu J, Wan XB, Huang XF, Chan KC, Hong MH, Wang LH, Long ZJ, Liu Q, Yan M, Lo YM, et al: Serologic antienzyme rate of Epstein-Barr virus DNase-specific neutralizing antibody segregates TNM classification in nasopharyngeal carcinoma. J Clin Oncol 28: 5202-5209, 2010.

26. Li Y, Wang K, Yin SK, Zheng HL and Min DL: Expression of Epstein-Barr virus antibodies EA-IgG, Rta-IgG, and VCA-IgA in nasopharyngeal carcinoma and their use in a combined diagnostic assay. Genet Mol Res 15, 2016.

27. Tiwawech D, Srivatanakul P, Karaluk A and Ishida T: Significance of plasma IgA and IgG antibodies to Epstein-Barr virus early and viral capsid antigens in Thai nasopharyngeal carcinoma. Asian Pac J Cancer Prev 4: 113-118, 2003.

28. Gourzones C, Gelin A, Bombik I, Klibi J, Vérillaud B, Guigay J, Lang P, Témam S, Schneider V, Amiel C, et al: Extra-cellular release and blood diffusion of BART viral micro-RNAs produced by EBV-infected nasopharyngeal carcinoma cells. Virol J 7: 271, 2010.

29. Yip TT, Ngan RK, Fong AH and Law SC: Application of circulating plasma/serum EBV DNA in the clinical management of nasopharyngeal carcinoma. Oral Oncol 50: 527-538, 2014.

30. Leung SF, Chan KC,Ma BB, Hui EP,MoF, Chow KC, Leung L, Chu KW, Zee B, Lo YM and Chan AT: Plasma Epstein-Barr viral DNA load at midpoint of radiotherapy course predicts outcome in advanced-stage nasopharyngeal carcinoma. Ann Oncol 25: 1204-1208, 2014.

31. Tan $\mathrm{CH}$ : Epstein-Barr virus, chemical carcinogens and nasopharyngeal carcinoma. Practical J Cancer: 58-59, 1992 (In Chinese).

32. Fang CY, Huang SY, Wu CC, Hsu HY, Chou SP, Tsai CH, Chang Y, Takada K and Chen JY: The synergistic effect of chemical carcinogens enhances Epstein-Barr virus reactivation and tumor progression of nasopharyngeal carcinoma cells. PLoS One 7: e44810, 2012.

33. Fang CY, Lee CH, Wu CC, Chang YT, Yu SL, Chou SP, Huang PT, Chen CL, Hou JW, Chang Y, et al: Recurrent chemical reactivations of EBV promotes genome instability and enhances tumor progression of nasopharyngeal carcinoma cells. Int J Cancer 124: 2016-2025, 2009.

34. Bhakta-Guha D and Efferth T: Hormesis: Decoding two sides of the same coin. Pharmaceuticals (Basel) 8: 865-883, 2015.

This work is licensed under a Creative Commons Attribution-NonCommercial-NoDerivatives 4.0 International (CC BY-NC-ND 4.0) License. 